\title{
Editors' overview
}

In his "Editor's Overview," published in the very first issue of Applied Psycholinguistics in February 1980, Sheldon Rosenberg reviewed the history that had led up to the founding of the journal. He wrote:

Clearly, one of the things that was missing from the field of applied psycholinguistics was a comprehensive, multidisciplinary and international journal dedicated to publishing the high-quality articles of workers who approach applied problems from the standpoint of basic research and theory in psycholinguistics and related areas of cognitive psychology.

Just as clearly, the gap has now been filled, thanks to Shel's vision, his willingness to take the initiative, and his investment of 4 years of hard work. Knowing how much of his time and professional energy have been absorbed by getting Applied Psycholinguistics on its feet, by building a readership, and by establishing and maintaining its rigorous methodological and theoretical standards, no one could fail to understand why Shel has chosen to rededicate himself to his own scholarly activities.

Shel has helped us greatly during the transition from his editorship to ours. We are grateful that he has agreed to serve as a member of the $A P$ Editorial Board, in which capacity he will aid us in maintaining the standards of excellence he set for the journal. Many of the articles published in this issue were handled by Shel, and the next issue will probably also contain some papers processed under his editorial supervision.

As with any change of editorship, some change of flavor will inevitably occur in the journal. This is signaled by AP's new color scheme and cover design, and may be reflected in a somewhat different mix of issues and topics as well, though the central mission of the journal remains exactly as Shel phrased it in 1980:

First, $A P$ is a comprehensive journal; that is, one that attempts to cover the entire range of problem areas in the field of applied psycholinguistics and to publish empirical, theoretical, methodological, and literature review articles. Second, $A P$ publishes articles in which applied problems are approached from the standpoint of basic research and theory in psycholinguistics and related areas of cognitive psychology. Third, we are interested in publishing not only narrowly focused papers, but ones which recognize the essential interrelations between the various subareas of applied psycholinguistics.

$A P$ 's audience includes psycholinguists, linguists, neurolinguists, sociolinguists, as well as researchers in child l inguage, speech and language pathology, secondlanguage acquisition, language education, cognitive sciences, reading, writing, and deaf education. Communication among specialists across these disciplinary borders is crucial to advancement of theory and of practice in psycholinguistics; our aim is that $A P$ should provide a forum for that communication. 
Editors' overview

Among the small changes we will introduce will be the occasional publication of theme issues, with one planned for 1985 and one for 1986 . We are now inviting original research reports, issue-oriented review papers, and theoretical discussions for the first two theme issues, on "The Psycholinguistics of Writing" and on "Language Loss."

\section{THE PSYCHOLINGUISTICS OF WRITING}

Papers on the development of writing, in preschool or school-age children and in adults, in both native and foreign languages, and on dysgraphia and other writing disorders, either developmental or acquired, are invited for a special issue devoted to the psycholinguistic processes involved in writing. Deadline for submission: 15 September 1984, for publication early in 1985.

\section{LANGUAGE LOSS}

Papers dealing with language loss are invited for a special issue, to be published in 1986. The topics for the issue will include the loss (or reorganization) of one's native language as a second language is learned; the loss of a language through disuse; the loss of a language that occurs in dementia and aphasia; lexical and rule loss as a language undergoes continued development, as in creolization, or as a language declines, as in language death; and loss of infants' prelinguistic auditory-perceptual or motor capabilities as a first language is acquired. Deadline for submission: 15 September 1985, for publication early in 1986.

Catherine E. Snow

Cambridge, Massachusetts

John L. Locke

March 1984

Boston, Massachusetts

March 1984 